\title{
Fetal Female Sex Ratio
}

National Cancer Institute

\section{Source}

National Cancer Institute. Fetal Female Sex Ratio. NCI Thesaurus. Code C124621.

The determination of the ratio of live female fetuses compared to the total number of live fetuses present in the uterus. The measurement may be expressed as a fraction or percentage. 